\title{
Uses of Augmented reality for urban utilities management
}

\author{
Ahmed KADDIOUI ${ }^{1,2}$, Isam SHAHROUR ${ }^{1}$, Ahmed El OIRRAK ${ }^{2}$ \\ ${ }^{1}$ Laboratoire de Génie Civil et géo-Environnement, Université de Lille, 5900 Lille, France \\ ${ }^{2}$ Laboratoire d'ingénierie des systèmes informatiques, Université Cadi Ayyad, Marrakech, \\ Maroc
}

\begin{abstract}
Augmented reality (AR) is based on supplementing the view of the physical world with a computer-generated content such as text, images videos, sound, 3D objects etc. The proliferation of smart mobile devices and their high computational capabilities combined with the possibility of GIS 3D visualization and interaction have enabled new kinds of mobile applications. AR is considered as an efficient technology for the underground utilities management. Damages to underground utility lines are considered as one of the major urban problems because incidents caused by unsafe digging practices can compromise community safety and disconnect people from vital services. A prospective study was conducted to identify examples and characteristics of each type of augmented reality. This paper summarizes researches about the types of AR and discuss how this technology could help in underground utilities repairing and maintenance. We present a new mobile location based augmented reality system using smart device sensors and the Real Time Kinematic (RTK) satellite navigation technology of ORPHEON network for the location accuracy. This system enables GIS data visualization to help field workers in outdoor maintenance of underground infrastructures.
\end{abstract}

Keywords: Augmented Reality, underground infrastructures, buried networks, GIS 3D visualization.

\section{Introduction}

Cities face a multitude of challenges, because of the fast growth of the population. Underground utilities that provide drinking water, electric power, sewage, and telecommunications, among other services have been gradually added leading to complex subsurface problems. However, information about the localization and condition of underground infrastructures are generally not easily available, impacting their maintenance and the urban development. The efficient management of these infrastructures is still considered as an unresolved problem for both maintenance and installation companies [1]. Due to the lack of information about the localization of buried utilities, soil excavating for maintenance could lead to utilities damage with sometimes large consequences on urban services supply. 
Generally, utilities companies use 2D maps for inspection of the underground assets, involving the tedious task of locating them correctly. Today, with the digital revolution, advanced systems for integrated management of buried networks could be used. These systems offer the possibility to conduct collaborative work for the design, construction and management of urban underground utilities. Tools for computer-aided design (CAD) are generally used in the design phase. However, these tools are not updated during the operating phase. We have also some difficulties related to crack detection to access the exact depth of some objects [2].

An integrated system for buried networks requires a client-server architecture. It should be able to extend the geographic information systems (GIS) features in terms of spatial databases and data analysis to data visualization objects and ubiquitous access. Augmented Reality (AR) constitutes a powerful tool for this requirement, because it provides both an integrated $3 \mathrm{D}$ view of the geospatial models and immediate feedback to users. It acts in an intuitive way for data capturing, data correction and surveying. Location awareness and visualization of invisible information are additional valuable features.

This paper presents the use of AR in the maintenance of buried urban utilities. First, it provides classification of the AR types, then presents some examples of AR uses in underground networks and finally proposes a novel AR system for the underground utilities management.

\section{Classification of AR types}

Augmented Reality is a real time, direct or indirect view of the physical "realworld" environment, which can be augmented by computer-generated sensory input such as sound, video, graphics or GPS and compass data [3]. The overlaid sensory information can be constructive (i.e. additive to the real environment), or destructive (i.e. masking of the real environment). AR is an interactive experience of the physical environment whose objects are enhanced by computer-generated perceptual information [4].

AR has five types that fall into two global categories: (i) Maker based AR which uses camera and visual cues and (ii) Marker-less based AR that use positional data such as mobile sensors data like GPS, gyroscope and compass.

\subsection{Marker-based AR}

Called also image recognition AR, Marker-based augmented reality anchors a computer-generated virtual contents to some forms of visual marker of the real life. A marker can be an image 2D or a Fudicial marker. A fudicial marker can be black and white images that consist of 2D image, barcodes or "quick response" (QR) codes [5] as shown in (Figure 1). Marker-based AR uses a camera with an AR software to detect AR markers as the location for virtual objects. The marker should be kept in front of the camera, once the marker is recognized by the camera frame, a virtual computer-generated content can be viewed on a screen and digital assets are placed into the scene at the location of the markers [6] (Figure 2). 


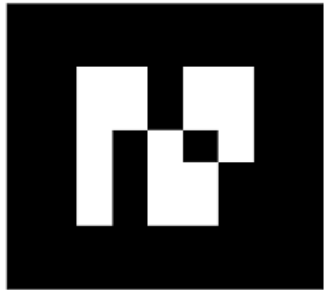

a) Quick response code

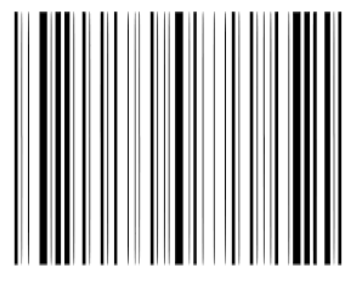

b) Barcode

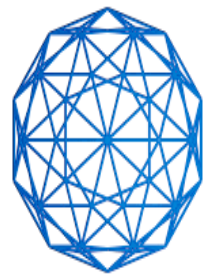

c) $2 \mathrm{D}$ image

Figure 1: Fudicial marker
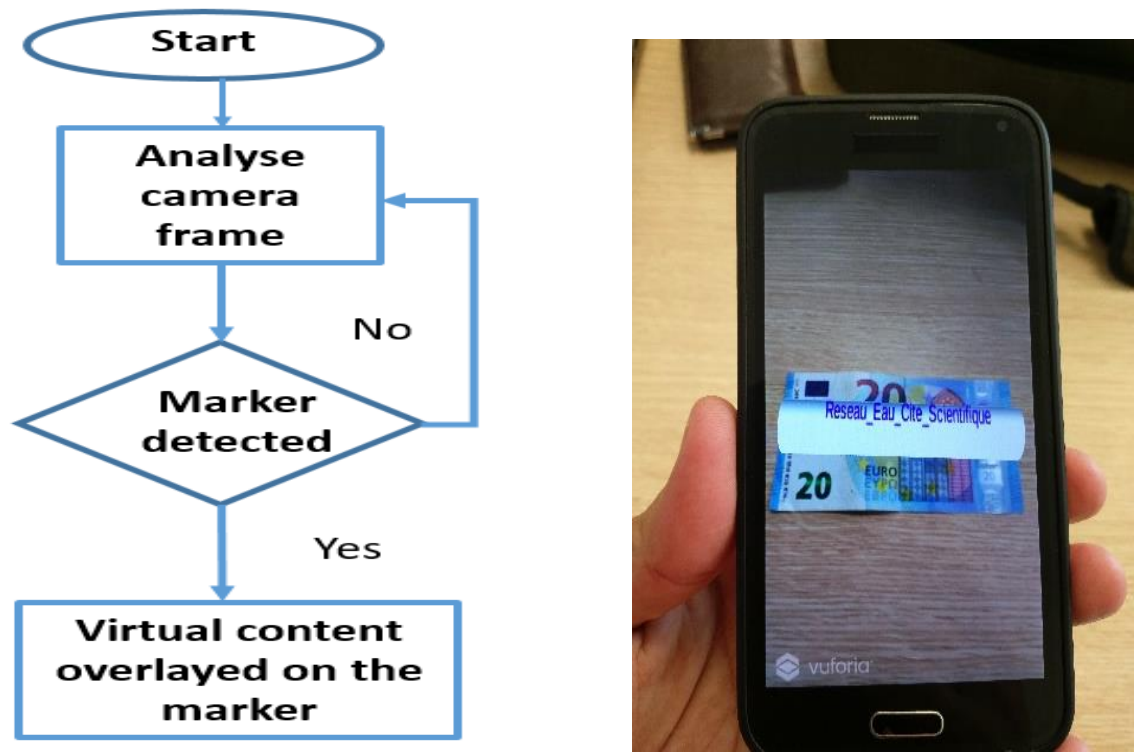

Figure 2: Marker-based augmented reality system

\subsection{Marker-less based AR}

The Marker-less AR technology doesn't need prior knowledge of a user's environment to overlay a $2 \mathrm{D}$ or $3 \mathrm{D}$ content into a scene and hold it to a fixed point in space. This technology uses data from camera systems, dedicated sensors and complex algorithms to accurately detect and map the physical environment - such as the location of points of interest. Drawing a map of the area, a Marker-less AR application enables placing virtual objects into a real context and have them in place without the need for any Fudicial marker [7] [8]. This technology includes different AR types such as Projection based AR, Location based AR, Superimposition based AR and Outlining based AR. Each type has specific characteristics (Table 1). 


\begin{tabular}{|c|c|c|c|}
\hline Category & Type & Examples & Characteristics \\
\hline $\begin{array}{l}\text { Marker based } \\
\text { AR }\end{array}$ & $\begin{array}{l}\text { Recognition } \\
\text { based AR }\end{array}$ & - Augment: [9] & $\begin{array}{l}\text {-Focuses on recognition of } \\
\text { objects } \\
\text {-Needs a camera to scan a } \\
\text { barcode or QR code. } \\
\text {-Add digital information to } \\
\text { the object. } \\
\text { - Once the object is } \\
\text { recognized it can be replaced } \\
\text { with another virtual object. }\end{array}$ \\
\hline \multirow[t]{4}{*}{$\begin{array}{l}\text { Marker-less } \\
\text { based AR }\end{array}$} & $\begin{array}{l}\text { Projection } \\
\text { based AR }\end{array}$ & -Aerial Burton: [10] & $\begin{array}{l}\text {-Functions using projection } \\
\text { onto objects can be used to } \\
\text { create deception about the } \\
\text { position, orientation and } \\
\text { depth of an object. } \\
\text {-Might eliminate the use of } \\
\text { special gear like head } \\
\text { mounted displays }\end{array}$ \\
\hline & $\begin{array}{l}\text { Location } \\
\text { based AR }\end{array}$ & $\begin{array}{l}\text { - Yelp Monocle: } \\
\text { [11] } \\
\text { - Instagram: [12] }\end{array}$ & $\begin{array}{l}\text {-Used for AR location } \\
\text { browsers } \\
\text {-Detecting the device } \\
\text { location and orientation by } \\
\text { reading its data sensors } \\
\text {-Predicting where the user is } \\
\text { looking } \\
\text {-Adding related information } \\
\text { on screen about specific } \\
\text { objects that can be seen from } \\
\text { the camera. }\end{array}$ \\
\hline & $\begin{array}{l}\text { Superimpositio } \\
\mathrm{n} \text { based AR }\end{array}$ & -Layar: [13] & $\begin{array}{l}\text { Provides an 'alternate' view } \\
\text { of the object in concern by: } \\
\text {-Replacing the entire view } \\
\text { with an augmented view of } \\
\text { the object; } \\
\text {-Replacing a portion of the } \\
\text { object view with an } \\
\text { augmented view. }\end{array}$ \\
\hline & $\begin{array}{l}\text { Outlining based } \\
\text { AR }\end{array}$ & $\begin{array}{l}-110 \text { Stories } \\
\text { Kickstarter }[14]\end{array}$ & $\begin{array}{l}\text { Solve human eye view } \\
\text { limitations like: } \\
\text {-looking at things for too } \\
\text { long; } \\
\text {-see well in low light } \\
\text { conditions } \\
\text {-Apps which perform } \\
\text { outlining use special } \\
\text { cameras. }\end{array}$ \\
\hline
\end{tabular}

Table 1. Summary of augmented reality categories and types. 


\section{Applications of Augmented Reality in underground networks}

The lifecycle management of the underground utilities including design, construction and maintenance are generally accomplished using different techniques and data formats [15]. Design falls within the domain of the Building information modeling (BIM) and computer aided design (CAD). Generally, 2D modelling is used. Since the maintenance could alter the original design, CAD tools are not adequate for the comprehensive management of underground utilities. Consequently, integrated system that provides storage capacity, visualization, and analysis capabilities associated with the Geographic Information Systems (GIS) is required. Recently, BIM and 3D GIS were used for both design and spatial data during the planning and construction phases as well as the system lifecycle management [16].

Recent advances in sensors, embedded microsystems, internet and wireless communications have led to the evolution of a new generation of distributed computing platforms and resulted in innovative systems for data representation, interaction and acquisition. AR is an emerging technology that provides overlaying virtual content seamlessly on the real world and has a great potential in the field of underground utilities management. It allows to visualize the underground assets [17]. An advanced system based on AR was developed for the visualization of subsurface infrastructures. A tablet is used as a display, an inertial measurement unit is incorporated, as well as a GPS antenna and a camera. Sensors incorporated in the device "tablet" make it bulky. This AR system allows an interactive planning and surveying of geospatial data and use real time kinematic RTK for solving the location problem [18]. The use of physical targets allows device's orientation with an accuracy below centimeter. The difficulty of this technique is related to the necessity to figure out the target points, which is very complex in dense cities. [8] Proposed an AR system that allows creating, reading, updating, and deleting data from a geospatial database through a mobile interface which is connected to Internet by means of a client-server architecture. This system can be deployed easily using only underground infrastructures data in CAD format.

Chicago city has deployed a system for both city mapping and assessing of underground infrastructure [19]. Some utility companies use the Ground-penetrating radar (GPR) as a remote non-destructive sensing technique for both underground infrastructure imaging and assess buried pipe condition assessment [20, 21,22]. [23] Proposed a GPR system integration with AR mobile-based positioning system. This system uses fundamentals of GPR sensing and the Google Tango AR technology. It can perform a circular GPR scan over a distance of $50 \mathrm{~m}$ and assigning a geographic coordinate accurately to detected underground features.

\section{Novel AR system for the underground utilities management}

The proposed AR system presents new features. It combines different emerging technologies to develop an AR mobile device (Smartphone or Tablet) for buried networks management and using a client-server architecture (Figure 3). 


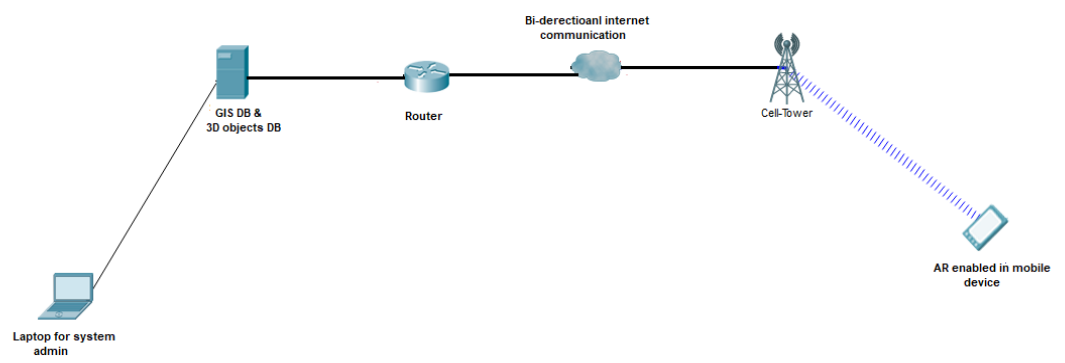

Figure 3: AR system Client-server architecture

This system integrates technologies in the domains of AR and 3D GIS. It aims at offering an AR Assistive System to help utility field workers to visualize the buried infrastructures on a Smartphone or a tablet Screen. This system provides a real time and high accuracy visualization of surrounding underground utilities (water, gas, sewerage, electricity, etc.). As this system is designed for maintenance of buried utilities, it should provide a localization accuracy. This is achieved by using the Real Time Kinematic (RTK) [24] satellite navigation of ORPHEON network [25]. This system provides an ergonomic easy to use interface (UI). The user could interact with the system and getting the results displayed on his device screen. The system allows bi-directional interactions between the GIS database, the 3D objects database and users. All changes on the GIS database would be automatically translated into 3D objects and synchronized with GIS databases and 3D objects database (figure 4). Users have informations precisely about the device position and orientation and the surrounding underground utilities.

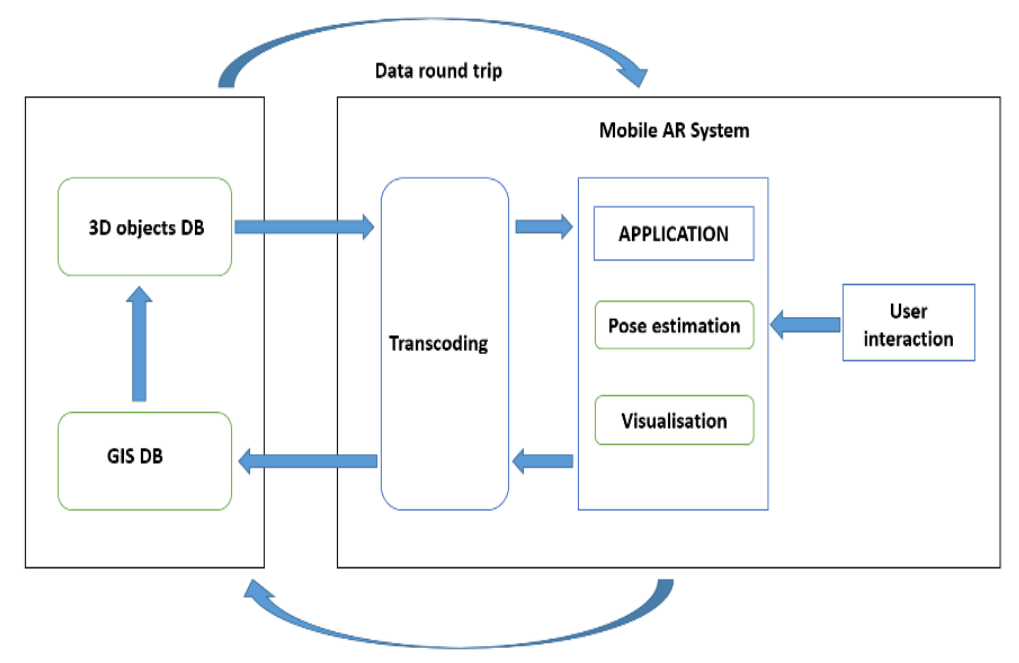

Figure 4: AR data round trip system 


\section{Conclusions}

The management of underground utilities constitutes a major urban concern. Today, it constitutes an important component of the Smart City. Augmented Reality (AR) offers powerful capacities in the field for the visualization of underground utilities in their 3D environment as well as the associated real-time informations. This paper presented AR classifications and pointed out the critical issues related to the use of AR in utilities management. It also presented an innovative mobile AR system for utilities management using the smartphone sensors for the localization of the device and hidden utilities tracking and visualization. This system uses the Real Time Kinematic (RTK) satellite navigation technology of ORPHEON network, which is available in France with a localization accuracy within some centimeters. In addition, this system has the capacity to connect to a server and update utilities informations.

\section{References}

1. Gamayunova, O., and Gumerova, E., 2016, "Solutions to the Urban Problems by Using of Underground Space," Procedia Eng., 165, pp. 1637-1642.

2. Curiel-EsparzaCanto-Perello, J., 2013, "Selecting Utilities Placement Techniques in Urban Underground Engineering," Arch. Civ. Mech. Eng., 13(2), pp. 276-285.

3. P. Milgram and F. Kishino, "A Taxonomy of Mixed Reality Visual Displays," IEICE Trans. Information Systems, vol. E77- D, no. 12, 1994, pp. 1321-1329.

4. The Lengthy History of Augmented Reality". Huffington Post. 15 May 2016.

5. Craig, Alan B. «Augmented Reality Hardware ». In Understanding Augmented Reality, 69-124. Elsevier, 2013.

6. A. Katiyar, K. Kalra, et C. Garg, "Marker Based Augmented Reality », Advances in Computer Science and Information Technology, vol. 2, no 5, p. 5, 2015. pp. 441-445.

7. https://www.marxentlabs.com/what-is-markerless-augmented-reality-dead-reckoning/

8. K. Yang, T. Brown, et K. Sung, "AR Object Manipulation on Depth-Sensing Handheld Devices », Applied Sciences, vol. 9, no 13, p. 2597, June 2019.

9. https://play.google.com/store/apps/details?id=com.ar.augment\&hl=fr

10. https://www.youtube.com/watch?v=1QXw3ylCYT0

11. (https://www.yelp.com)-

12. https://www.instagram.com

13. https://edshelf.com/tool/layar/

14. http://110stories.com

15. Sevket Demirci, Enes Yigit, Ismail H. Eskidemir, and Caner Ozdemir. 2012. Ground penetrating radar imaging of water leaks from buried pipes based on backprojection method. NDT and E International 47 (2012), 35-42.

16. Dryver Huston, Tian Xia, Yu Zhang, Taian Fan, Dan Orfeo, and Jonathan Razinger. 2017. Urban underground infrastructure mapping and assessment. April (2017), $101680 \mathrm{M}$.

17. Amr Ahmed, Yu Zhang, Dylan Burns, Dryver Huston, and Tian Xia. 2016. Design of UWB antenna for air-coupled impulse ground-penetrating radar. IEEE Geoscience and Remote Sensing Letters 13, 1 (2016), 92-96. 
18. G. Schall, S. Zollmann, et G. Reitmayr, "Smart Vidente: advances in mobile augmented reality for interactive visualization of underground infrastructure ", Personal and Ubiquitous Computing, vol. 17, no 7, p. 1533-1549, oct. 2013.

19. https://www.cnet.com/news/chicago-maps-its-underground-maze-rahm-emanuel/

20. Yu Zhang, Anbu Selvam Venkatachalam, Dryver Huston, and Tian Xia. 2014. Advanced signal processing method for ground penetrating radar feature detection and enhancement. In Nondestructive Characterization for Composite Materials, Aerospace Engineering, Civil Infrastructure, and Homeland Security 2014, Vol. 9063.

21. Yu Zhang, Anbu S Venkatachalam, and Tian Xia. 2015. Ground-penetrating radar railroad ballast inspection with an unsupervised algorithm to boost the region of interest detection efficiency. Journal of Applied Remote Sensing 9, 1 (2015), 095058.

22. Tian Xia, Xianlei Xu, Anbu Vekatachalam, and Dryver Huston. 2012. Development of a High Speed UWB GPR for Rebar Detection. In 14th International Conference on Ground Penetrating Radar (GPR).

23. M. Pereira, D. Burns, D. Orfeo, R. Farrel, D. Hutson, et T. Xia, « New GPR System Integration with Augmented Reality Based Positioning », in Proceedings of the 2018 on Great Lakes Symposium on VLSI - GLSVLSI '18, Chicago, IL, USA, 2018, p. 341-346.

24. Real Time Kinematic (RTK) satellite navigation. http://en.wikipedia.org/wiki/Real_Time_Kinematic Last accessed 18 September 2016.

25. ORPHEON network http://reseau-orpheon.fr/le-reseau-orpheon/ 